\title{
PEMBUKAAN MULUT MAKSIMAL SUKU BATAK KELOMPOK UMUR 17-22 TAHUN
}

\author{
(MAXIMAL MOUTH OPENING IN BATAKNESE WITHIN THE AGE \\ GROUP OF 17-22 YEARS OLD)
}

\author{
Rehulina Ginting, May Purba \\ Departemen Biologi Oral \\ Fakultas Kedokteran Gigi, Universitas Sumatera Utara \\ Jl. Alumni No.2 Kampus USU Medan \\ E-mail: rehulinagtgdrg@gmail.com
}

\begin{abstract}
Maximal mouth opening is the greatest distance between the incisal edge of the maxillary and mandibular central incisors in the midline when the mouth is open maximally. Maximal mouth opening is an important parameter to evaluate the function of temporomandibular joint and masticatory muscle status. The purpose of this study was to investigate the range of maximal mouth opening in Bataknese within the age group of 17-22 years old. The design of study was an analytical description of cross sectional design study. The result showed that there was a significant difference of maximal mouth opening between gender $(p<0,05)$ but not among age groups $(p>0,05)$. In conclusion, the average of active maximal mouth opening was $44,52 \pm 7,27 \mathrm{~mm}$ for men and $38,13 \pm 4,16 \mathrm{~mm}$ for women; the average of passive maximal mouth opening was 46, $28 \pm 6,79 \mathrm{~mm}$ for men and $39,59 \pm 4,62 \mathrm{~mm}$ for women.
\end{abstract}

Key words: active maximal mouth opening, passive maximal mouth opening

\begin{abstract}
Abstrak
Pembukaan mulut maksimal adalah jarak terjauh antara tepi insisal insisivus sentralis maksila dan mandibula pada garis tengah gigi ketika mulut terbuka maksimal. Pembukaan mulut maksimal merupakan parameter yang penting untuk mengevaluasi fungsi sendi temporomandibula dan status otot mastikasi. Penelitian ini bertujuan untuk mengetahui ukuran pembukaan mulut maksimal suku Batak kelompok umur 17-22 tahun. Jenis penelitian adalah deskriptif analitik dengan rancangan cross sectional. Hasil penelitian menunjukkan terdapat perbedaan yang signifikan pembukaan mulut maksimal antar jenis kelamin $(\mathrm{p}<0,05)$ namun tidak terdapat perbedaan yang signifikan antar masing-masing kelompok umur (p>0,05). Sebagai kesimpulan, rerata pembukaan mulut maksimal aktif pada laki-laki adalah 44,52 \pm 7,27 mm dan pada perempuan $38,13 \pm 4,16 \mathrm{~mm}$, nilai rerata pembukaan mulut maksimal pasif pada laki-laki adalah 46,28 $\pm 6,79 \mathrm{~mm}$ dan pada perempuan $39,59 \pm 4,62 \mathrm{~mm}$.
\end{abstract}

Kata kunci: pembukaan mulut maksimal aktif, pembukaan mulut maksimal pasif

\section{PENDAHULUAN}

Pemeriksaan pembukaan mulut maksimal umumnya dilakukan melalui pengukuran jarak interinsisal ketika pasien membuka mulutnya semaksimal mungkin. ${ }^{1}$ Oleh karena itu pembukaan mulut maksimal didefinisikan sebagai jarak terjauh antara tepi insisal insisivus sentralis maksila dan mandibula pada midline ketika mulut terbuka maksimal. ${ }^{2,3}$ Pengukuran jarak interinsisal ini memiliki keuntungan berupa titik ukur yang relatif lebih permanen dan lebih mudah ditentukan. ${ }^{4,5}$ Pembukaan mulut maksimal merupakan salah satu parameter yang penting untuk mengevaluasi fungsi sendi temporomandibula dan status otot mastikasi. ${ }^{2,6}$ Pembukaan mulut maksi-mal yang normal juga diperlukan untuk memungkin-kan klinisi melakukan pemeriksaan oral yang leng-kap dengan nyaman. ${ }^{7,8}$

Ukuran pembukaan mulut maksimal bervariasi pada populasi yang berbeda. ${ }^{7}$ Ukuran pembukaan mulut maksimal dipengaruhi oleh beberapa faktor meliputi usia, ${ }^{4,8,9}$ jenis kelamin, ${ }^{4,8}$ ras, ${ }^{9,10}$ tinggi badan, 
berat badan, ${ }^{8,11}$ struktur sendi dan otot, morfologi fasial, $^{8,12}$ serta ukuran mandibula dan basis kranial. ${ }^{4,10}$

Pembukaan mulut maksimal terdiri atas pembukaan mulut maksimal aktif ${ }^{6,10,11}$ dan pasif. ${ }^{10,13}$ Pembukaan mulut maksimal aktif diukur sebagai jarak antara tepi insisal insisivus sentralis maksila dan mandibula saat mulut terbuka maksimal tanpa bantuan jari. ${ }^{6,10}$ Pembukaan mulut maksimal aktif dapat digunakan sebagai parameter untuk metode skrining dalam mendeteksi keadaan-keadaan yang mempengaruhi sendi temporomandibula dan otot mastikasi. ${ }^{6}$ Penelitian yang dilakukan oleh Casanova-Rosado dkk. menunjukkan bahwa rata-rata pembukaan mulut maksimal aktif pada orang dewasa dan dewasa muda berumur 14-24 tahun di Meksiko adalah 46,61 \pm 7,37 mm. ${ }^{10}$ Penelitian Sohail, dkk. di Uni Emirat Arab menunjukkan bahwa rata-rata pembukaan mulut maksimal aktif pada mahasiswa kelompok umur 19-24 tahun adalah 53,12 \pm 7,95 mm. ${ }^{2}$

Pada pembukaan mulut maksimal pasif, jarak interinsisal diukur ketika mandibula dibuka dengan bantuan lebar empat jari (jari telunjuk, jari tengah, jari manis, dan jari kelingking) yang disejajarkan antara tepi insisal insisivus sentralis maksila dan mandibula. ${ }^{13,14}$ Pembukaan mulut maksimal pasif dapat digunakan sebagai suatu teknik untuk diferensiasi dan pemeriksaan keterbatasan pembukaan mulut akibat otot atau sendi. ${ }^{1}$ Penelitian Casanova-Rosado, dkk. pada kelompok umur 14-24 tahun di Meksiko menunjukkan bahwa rata-rata jarak interinsisal saat pembukaan mulut maksimal pasif adalah 49,48 \pm $6,59 \mathrm{~mm} .{ }^{10}$ Pada penelitian Zawawi, dkk. pada kelompok umur 21-42 tahun di Amerika diperoleh rata-rata jarak interinsisal pembukaan mulut pasif sebesar 48,8 mm. ${ }^{13}$

Berdasarkan uraian di atas dan belum adanya penelitian mengenai ukuran pembukaan mulut maksimal di Kota Medan, maka tujuan penelitian ini adalah untuk mengobservasi ukuran pembukaan mulut maksimal pada 60 orang suku Batak kelompok umur 17-22 tahun.

\section{BAHAN DAN METODE}

Penelitian ini merupakan penelitian deskriptif analitik dengan rancangan cross sectional dengan mengukur jarak interinsisal pembukaan mulut maksimal aktif dan pasif pada suku Batak kelompok umur 17-22 tahun. Alat yang digunakan dalam penelitian ini adalah kaliper digital Krisbow brand model kw 06-358 (150 mm x 6") dengan ketelitian 0,01 mm Gambar 1.

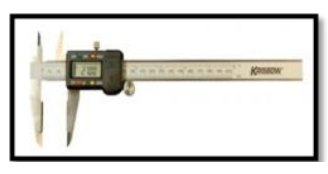

Gambar 1. Kaliper digital Krisbow

Sampel pada penelitian ini sebanyak 60 orang yang dibagi atas 30 orang laki-laki dan 30 orang perempuan sesuai dengan kriteria inklusi yaitu memiliki gigi-geligi rahang atas dan rahang bawah yang lengkap $\left(\mathrm{I}_{1}-\mathrm{M}_{2}\right)$, suku Batak dua generasi, umur 1722 tahun, oklusi Klas I Angle, tidak ada atrisi, erosi, fraktur atau tambalan pada gigi insisivus sentralis maksila dan mandibula, tidak ada pergeseran midline, tidak ada keluhan rasa sakit, bunyi, atau keterbatasan pembukaan mulut saat membuka atau menutup mulut, serta tidak pernah menjalani perawatan ortodonti atau bedah rahang.

Untuk mengukur jarak interinsisal pembukaan mulut maksimal maka pertama-tama subyek penelitian diinstruksikan untuk duduk dengan posisi tegak dimana kepala subyek didukung oleh sandaran kursi. Subyek penelitian diminta untuk membuka mulutnya semaksimal mungkin tanpa bantuan jari (pembukaan mulut maksimal aktif). Selanjutnya dilakukan pengukuran pembukaan mulut maksimal aktif dengan menggunakan kaliper digital. Subjek penelitian kemudian diminta untuk kembali membuka mulutnya semaksimal mungkin dengan bantuan empat jari (jari telunjuk, jari tengah, jari manis dan jari kelingking) subjek penelitian (pembukaan mulut maksimal pasif). Pembukaan mulut maksimal pasif kemudian diukur dengan menggunakan kaliper digital. Jarak interinsisal pembukaan mulut maksimal aktif dan pasif diukur dari tepi insisal insisivus sentralis maksila ke tepi insisal insisivus sentralis mandibula pada midline gigi.

Untuk melihat apakah ada perbedaan jarak interinsisal pembukaan mulut maksimal aktif dan pasif antara laki-laki dan perempuan suku Batak dilakukan uji T tidak berpasangan.

Untuk melihat apakah ada perbedaan yang signifikan jarak interinsisal pembukaan mulut maksimal aktif dan pasif antara kelompok umur 17, 18, 19, 20, 21 dan 22 tahun dilakukan uji Anova satu arah.

\section{HASIL}

Tabel 1 menunjukkan ada perbedaan yang signifikan jarak interinsisal pembukaan mulut maksimal aktif dan pasif antara laki-laki dan perempuan suku Batak kelompok umur 17-22 tahun $(\mathrm{p}<0,05)$. 
Tabel 1. Perbedaan jarak interinsisal pembukaan mulut maksimal aktif dan pasif antara laki-laki dan perempuan

\begin{tabular}{ccccc}
\hline Jenis kelamin & $\mathrm{n}$ & $\begin{array}{l}\text { Rerata jarak interinsisal pembukaan } \\
\text { mulut maksimal aktif }(\mathrm{mm})\end{array}$ & $\mathrm{p}$ & $\begin{array}{l}\text { Rerata jarak interinsisal pembukaan } \\
\text { mulut maksimal pasif (mm) }\end{array}$ \\
\hline Laki-laki & 30 & $44,52 \pm 7,27$ & $0,000 *$ & $46,28 \pm 6,79$ \\
Perempuan & 30 & $38,13 \pm 4,16$ & $39,59 \pm 4,62$ \\
\hline
\end{tabular}

Uji T tidak berpasangan, *signifikan $\mathrm{p}<0,05$

Tabel 2 menunjukkan tidak terdapat perbedaan yang signifikan jarak interinsisal pembukaan mulut maksimal aktif dan pasif antar masing-masing kelompok umur 17, 18, 19, 20, 21, dan 22 tahun ( $p>0,05$ ).

Tabel 2. Perbedaan jarak interinsisal pembukaan mulut maksimal aktif dan pasif antar kelompok umur

\begin{tabular}{|c|c|c|c|c|c|}
\hline $\begin{array}{l}\text { Kelompok umur } \\
\text { (tahun) }\end{array}$ & $\mathrm{n}$ & $\begin{array}{l}\text { Rerata jarak interinsisal pembukaan } \\
\text { mulut maksimal aktif }(\mathrm{mm})\end{array}$ & $\mathrm{p}$ & $\begin{array}{l}\text { Rerata jarak interinsisal pembukaan } \\
\text { mulut maksimal pasif }(\mathrm{mm})\end{array}$ & $\mathrm{p}$ \\
\hline 17 & 3 & $41,79 \pm 7,13$ & & $43,99 \pm 6,87$ & \\
\hline 18 & 5 & $41,74 \pm 8,48$ & & $43,44 \pm 9,33$ & \\
\hline 19 & 21 & $40,97 \pm 7,21$ & 0,983 & $42,69 \pm 7,23$ & 0,975 \\
\hline 20 & 14 & $40,62 \pm 3,23$ & & $41,83 \pm 3,24$ & \\
\hline 21 & 9 & $42,89 \pm 10,10$ & & $44,24 \pm 9,49$ & \\
\hline 22 & 8 & $41,28 \pm 5,76$ & & $43,31 \pm 5,89$ & \\
\hline
\end{tabular}

Uji Anova satu arah, signifikan $\mathrm{p}<0,05$

\section{PEMBAHASAN}

Ukuran pembukaan mulut maksimal yang normal diperlukan sebagai parameter pembukaan mulut maksimal yang dapat ditoleransi pasien dalam perawatan gigi dan mulut dan juga sebagai metode skrining untuk mendeteksi kelainan fungsi sendi tempromandibula. Pembukaan mulut yang melebihi ukuran normal, misalnya perawatan gigi yang menyebabkan terbukanya mulut lebar dan lama, dapat mengakibatkan kelainan sendi temporomandibula seperti robeknya ligamen temporomandibula. Pembukaan mulut yang kurang dari ukuran normal antara lain merupakan indikasi kelainan sendi temporomandibula seperti dislokasi sendi, ankilosis, ataupun adhesi sendi temporomandibula. ${ }^{17}$

Penelitian tentang pembukaan mulut maksimal telah banyak dilakukan di negara-negara lain tetapi belum ada penelitian tentang pembukaan mulut maksimal di Indonesia khususnya di Kota Medan. Oleh karena itu penelitian ini dilakukan pada suku Batak sebagai suku terbesar yang ada di Sumatera Utara untuk mengetahui estimasi pembukaan mulut maksimal pada suku Batak sehingga dapat dibedakan dengan ukuran pembukaan mulut maksimal pada ras lain. Sampel pada penelitian ini berumur 17-22 tahun karena pada kelompok umur ini pertumbuhan rahang sudah berhenti sehingga tidak lagi terjadi pertambahan panjang mandibula yang dapat mempengaruhi ukuran pembukaan mulut maksimal. Sampel dipilih dengan oklusi klas I Angle karena oklusi Klas I Angle merupakan kriteria oklusi yang normal.

Hasil penelitian ini menunjukkan bahwa jarak interinsisal pembukaan mulut maksimal aktif pada laki-laki yaitu 44,52 \pm 7,27 mm dan pada perempuan adalah $38,13 \pm 4,16 \mathrm{~mm}$, sedangkan jarak interinsisal pembukaan mulut maksimal pasif pada lakilaki adalah 46,28 $\pm 6,79 \mathrm{~mm}$ dan pada perempuan adalah 39,59 $\pm 4,62 \mathrm{~mm}$. Hasil uji T tidak berpasangan terhadap jarak interinsisisal pembukaan mulut maksimal aktif dan pasif antara laki-laki dan perempuan (Tabel 1) menunjukkan ada perbedaan jarak interinsisal pembukaan mulut maksimal aktif dan pasif yang signifikan antara laki-laki dan perempuan suku Batak kelompok umur 17-22 tahun, yang mana jarak interinsisal pembukaan mulut maksimal aktif dan pasif pada laki-laki lebih besar dari perempuan $(\mathrm{p}=0,000)$. Hasil penelitian ini sesuai dengan penelitian Casanova-Rosado terhadap kelompok umur 14-24 tahun di Meksiko, dimana jarak interinsisal pembukaan mulut maksimal aktif dan pasif pada laki-laki lebih besar dari perempuan. ${ }^{10}$ Adanya perbedaan lebar pembukaan mulut maksimal antara laki-laki dan perempuan dapat diakibatkan oleh beberapa faktor. Casanova-Rosado menyatakan bahwa perbedaan lebar pembukaan mulut maksimal antara laki-laki dan perempuan dipengaruhi ukuran fisik, dimana laki-laki umumnya lebih besar daripada perempuan, sehingga struktur tulang kepala dan wajah pada laki-laki lebih besar daripada perempuan. ${ }^{10}$ Sawair, dkk. menyatakan bahwa perbedaan lebar 
pembukaan mulut maksimal antara laki-laki dan perempuan terjadi akibat adanya perbedaan panjang mandibula. Semakin panjang mandibula, semakin besar sendi engsel dapat berotasi sehingga pembukaan mulut maksimal semakin besar. ${ }^{6}$

Hasil uji Anova satu arah terhadap jarak interinsisal pembukaan mulut maksimal aktif dan pasif antar kelompok umur (Tabel 2) menunjukkan tidak terdapat perbedaan yang signifikan antar tiap kelompok umur 17-22 tahun. Hasil penelitian ini juga sesuai dengan penelitian Casanova-Rosado terhadap kelompok umur 14-24 tahun di Meksiko, dimana tidak ada perbedaan jarak interinsisal pembukaan mulut maksimal aktif dan pasif antar kelompok umur. ${ }^{10}$ Ukuran pembukaan mulut maksimal akan meningkat setelah lahir hingga dewasa, dan kemudian menurun secara bertahap selama proses penuaan. ${ }^{4,5} \mathrm{Pe}-$

\section{DAFTAR PUSTAKA}

1. Al-Tuhafi AA. Assesment of mouth opening limitation in myogenic temporomandibular disorder patient. Al-Rafidain Dent J 2005; 5(2): 180-4.

2. Sohail A, Amjad A. The range of inter-incisal opening among university students of Ajman, UAE. Pakistan Oral \& Dent J 2011; 31(1): 37.

3. Singh AM. A study to establish the normal range of mouth opening of Jamshedpur population. Guident 2012; 98-100.

4. Yao KT, Lin CC, Hung CH. Maximum mouth opening of ethnic Chinese in Taiwan. J Dent Sci 2009; 4(1): 40-4.

5. Kumar A, Mehta R, Goel M, Dutta S, Hooda A. Maximal mouth opening in Indian children using a new method. J f Cranio-Maxillary Diseases 2012; 1(2): 79-85.

6. Sawair FA, Hassoneh YM, Al-Zawawi BM, Baqain ZH. Maximum mouth opening; Associated factors and dental significance. Saudi Med J 2010; 31(4): 370.

7. Khare N, Patil SB, Kale SM, Sumeet J, Sonali I, Sumeet B. Normal mouth opening in an adult Indian population. J Maxillofac Oral Surg 2012; 11(3): 309-13.

8. Hamad SA, Al Kamali RK, Ali HM. The normal range of mouth opening in Kurdish population and its correlation to age, sex, height, and weight. Zanco J Med Sci 2010; 14(3): 1-5.

9. Ezirganli S, Kara MI, Kucuk D, Ozan F. Investigation amount of maximum mouth opening and association with temporomandibular joint disorders in Turkish adult population. J Dent Fac Ataturk Uni 2013; 21(1): 58 . ningkatan ukuran pembukaan mulut maksimal setelah lahir hingga dewasa terjadi akibat pertumbuhan mandibula. Pertumbuhan mandibula berakhir pada umur sekitar 15 tahun untuk wanita dan sekitar 17 tahun untuk pria. ${ }^{16}$ Pada penelitian ini, sampel yang digunakan berumur 17-22 tahun sehingga tidak lagi terjadi pertumbuhan mandibula yang dapat mengakibatkan perbedaan pembukaan mulut maksimal baik aktif maupun pasif antar kelompok umur. Sebagai kesimpulan, terdapat perbedaan jarak interinsisal pembukaan mulut maksimal aktif dan pasif antara laki-laki dan perempuan, yang mana jarak interinsisal pembukaan mulut maksimal aktif dan pasif pada laki-laki lebih besar secara signifikan daripada perempuan.

10. Casanova-Rosado JF. Clinical characterization of mouth opening among Mexican adolescents and young adults. J f Dent Sci 2012; 7: 81-4.

11. de Sousa LM, Nagamine HM, Chaves TC, Grossi $\mathrm{DB}$, Regalo SCH, de Oliveira AS. Evaluation of mandibular range of motion in Brazilian children and its correlation to age, height, weight, and gender. Braz Oral Res 2008; 22(1): 61-6.

12. Fukui $\mathrm{T}$, Tsuruta $\mathrm{M}$, Murata $\mathrm{K}$, Wakimoto $\mathrm{Y}$, Tokiwa H, Kuwahara Y. Correlation between facial morphology, mouth opening ability, and condylar movement during opening-closing jaw movements in female adults with normal occlusion. European $\mathbf{J}$ f Orthodontics 2002; 24: 327.

13. Zawawi KH, Al-Badawi EA, Lobo SL, Melis M, Mehta NR. An index for the measurement of normal maximum mouth opening. J f Canadian Dent Association 2003; 69(11): 73.

14. Abou-Atme YS, Chedid N, Melis M, Zawawi KH. Clinical measurement of normal maximum mouth opening in children. J f Craniomand Practice 2008; 26(3). 1-5.

15. Melly Febrida. Orang Indonesia paling pendek seASEAN?. 24 April 2014. <www. health. liputan6. com.> (25 Januari 2015).

16. Rahardjo P. Ortodonti dasar. Surabaya: Airlangga University Press, 2009: 13.

17. Okeson JP. Functional anatomy and biomechanics of the masticatory system. In: Management of temporomandibular disorders and occlusion. Missouri: Elsevier Mosby, 2008: 300-16. 